\title{
Gastric emptying of liquids in rats dehydrated by water deprivation
}

E.C.E. Baracat and E.F. Collares

\author{
Departamento de Pediatria and Núcleo de Medicina e Cirurgia Experimental, \\ Faculdade de Ciências Médicas, Universidade Estadual de Campinas, \\ Campinas, SP, Brasil
}

\section{Correspondence \\ E.C.E. Baracat \\ Departamento de Pediatria \\ Faculdade de Ciências Médicas Universidade Estadual de Campinas 13081-970 Campinas, SP Brasil}

Publication supported by FAPESP.

Received March 10, 1997 Accepted September 9, 1997

\begin{abstract}
The gastric emptying of liquids was investigated in male Wistar rats ( 8 to 10 weeks old, 210-300 g) dehydrated by water deprivation. In this model of dehydration, weight loss, hematocrit and plasma density were significantly higher in the dehydrated animals than in the control groups after 48 and $72 \mathrm{~h}$ of water deprivation $(\mathrm{P}<0.05)$. Three test meals (saline $(\mathrm{N}=10)$, water $(\mathrm{N}=10)$ and a WHO rehydrating solution containing in one liter $90 \mathrm{mEq}$ sodium, $20 \mathrm{mEq}$ potassium, $80 \mathrm{mEq}$ chloride and $30 \mathrm{mEq}$ citrate $(\mathrm{N}=10)$ ) were used to study gastric emptying following water deprivation for 24,48 and $72 \mathrm{~h}$. After $72 \mathrm{~h}$, gastric emptying of the water (39.4\% retention) and rehydrating solution (49.2\% retention) test meals was significantly retarded compared to the corresponding control groups $(\mathrm{P}<0.05$, Mann-Whitney test). The 72-h period of deprivation was used to study the recovery from dehydration, and water was supplied for 60 or 120 min after 67 $\mathrm{h}$ of deprivation. Body weight loss, hematocrit and plasma density tended to return to normal when water was offered for $120 \mathrm{~min}$. In the animals supplied with water for $60 \mathrm{~min}$, there was a recovery in the gastric emptying of water while the gastric emptying of the rehydrating solution was still retarded $(53.1 \%$ retention; $\mathrm{P}<0.02$, KruskalWallis test). In the group supplied with water for $120 \mathrm{~min}$, the gastric emptying of the rehydrating (51.7\% retention) and gluco-saline (46.0\% retention) solutions tended to be retarded $(\mathrm{P}=0.04$, Kruskal-Wallis test). In this model of dehydration caused by water deprivation, with little alteration in the body electrolyte content, gastric emptying of the rehydrating solution was retarded after rehydration with water. We conclude that the mechanisms whereby receptors in the duodenal mucosa can modify gastric motility are altered during dehydration caused by water deprivation.
\end{abstract}

\section{Introduction}

The sense of thirst is a basic instinct in animals and constitutes an emergency mechanism for correcting liquid deficit (1). The various systems involved in controlling thirst include the volume receptors located on the walls of the right and left atria, the renalangiotensin-aldosterone complex, antidi-
Key words

- Gastric emptying

- Dehydration

- Water deprivation

...................... 
is based on maintaining animals in high temperature environments (5), with a consequent loss of electrolytes through sweating or via alterations in the ion and water content of saliva $(6,7)$. Studies investigating the oral replacement of liquids generally employ an intestinal water loss model because of the action of enteropathogens (8-10). In such experiments, the replacement liquids usually have a water and ion composition similar to that of the model being used.

The role of the gastrointestinal tract in maintaining the water equilibrium of a dehydrated individual is determined initially by its capacity to accommodate and empty an ingested solution and also by the absorptive capacity of the intestinal mucosa. The motor activity of the stomach is controlled by the coordinated distention and contraction of smooth muscle cells. The latter are under the influence of intrinsic and extrinsic nerve fibers as well as hormones released locally in response to the presence of gastric contents (11). In general, these hormones function in consonance with and are integrated to vagal and hypothalamic stimuli (12-14).

The stomach receives efferent parasympathetic fibers from the vagus nerve, the cells of which originate in the central nervous system and are responsible for increases in gastric tonus. Thus, gastric emptying can be modulated by central neuronal stimulation. The phenomenon of thirst, by acting preferentially through central control mechanisms, may influence gastric motility and, consequently, gastric emptying because of the activation of neurohormone connections between the hypothalamus and the stomach. In situations of isolated water deprivation (hydropenia) the influence of the hypothalamus is unknown. In addition, it is possible that local control mechanisms involving jejunal and duodenal receptors can also interfere with the gastric motor response in cases of thirst.

The objective of the present study was to investigate the effects of water deprivation on the gastric emptying of rehydrating solutions.

\section{Material and Methods}

Male Wistar rats (8 to 10 weeks old, 210$300 \mathrm{~g}$ ) were obtained from the Central Animal House of Universidade Estadual de Campinas, Brazil, and adapted to laboratory conditions for 7 days during which they were kept on a 12-h light/dark cycle with free access to water and food. Twenty-four hours before the experiments, the animals were placed in individual cages with or without water, but with access to dry ration.

All animals were weighed at the beginning of the study, after 24, 48 and $72 \mathrm{~h}$ of water deprivation, as well as prior to and after the partial administration of liquid. They were weighed again before the gastric emptying test when blood samples were also collected.

The values for weight loss (as percent of weight), hematocrit, and plasma density obtained for rats deprived of water for $72 \mathrm{~h}$ were significantly different from those of control animals and this validates the model of dehydration based on water deprivation alone.

Gastric emptying was studied in three phases.

\section{Phase 1: total water deprivation}

Twenty-four-hour group. Thirty animals were kept without water or ration for $24 \mathrm{~h}$. At the end of the period, all animals were submitted to a gastric emptying test with saline, water and WHO rehydrating solution meals (10 rats/meal). For each group, fasting control animals receiving water ad libitum over the same period of time and the same meals were used.

Forty-eight-hour group. Thirty animals were kept without water for $48 \mathrm{~h}$, and 30 control animals received water ad libitum. During the first $24 \mathrm{~h}$, the animals were pro- 
vided with food ad libitum after which the ration was withdrawn. Subsequently, the rats were separated into subgroups (10 rats/subgroup) for the study of gastric emptying using the same meals as for the 24-h group.

Seventy-two-hour group. Thirty animals were deprived of drinking water for $72 \mathrm{~h}$ and 30 control animals received water ad libitum. During the first $48 \mathrm{~h}$, the animals received food ad libitum after which the ration was withdrawn. The test meals given for the study of gastric emptying were the same as those described above.

\section{Phase 2: partial deprivation with water provided for $60 \mathrm{~min}$}

Twenty animals were deprived of water for $67 \mathrm{~h}$ and then offered water for $60 \mathrm{~min}$. After this, water was withdrawn until the end of the 72-h period.

The gastric emptying of two meals (water and WHO rehydrating solution) was studied in 10 animals for each meal. Another 20 control animals received water ad libitum (10 rats/meal) while 20 animals received no water (10 rats/meal) over the same period of time.

Phase 3: partial deprivation with water provided for $120 \mathrm{~min}$

Twenty animals were deprived of water for $67 \mathrm{~h}$ and were offered liquid for $120 \mathrm{~min}$. Thereafter, water was withdrawn again until the end of the 72-h period.

The gastric emptying of two test meals (WHO rehydrating solution and gluco-saline solution) was studied in 10 animals for each meal. Twenty control animals (10 rats/ meal) received water ad libitum and another 20 rats (10 rats/meal) were deprived of liquids during the study period.

The test meals were administered at a dose of $2 \mathrm{ml} / 100 \mathrm{~g}$ body weight with the addition of phenolsulfonphthalein to a final concentration of $6 \mathrm{mg} / 100 \mathrm{ml}$ of solution
(15).

The test meals administered included sodium chloride solution $(0.9 \%=9 \mathrm{~g} / \mathrm{dl})$, water, a WHO rehydrating solution and a glucosaline solution containing $111 \mathrm{mM}$ glucose and $90 \mathrm{mM}$ sodium chloride. When dissolved in one liter of water, the resulting solution of a powdered WHO rehydration sachet contains $90 \mathrm{mEq}$ sodium, $20 \mathrm{mEq}$ potassium, $80 \mathrm{mEq}$ chloride and $30 \mathrm{mEq}$ citrate.

The osmotic values of the meals employed, except for water, were determined with an osmometer (Advanced Digimatic Osmometer, model 3DII, Advanced Instruments, Inc., Medkam Heights, MA) and found to be $305 \mathrm{mOsm} / \mathrm{l}$ for the $0.9 \%$ sodium chloride solution, $309 \mathrm{mOsm} / \mathrm{l}$ for the WHO rehydrating solution and $283 \mathrm{mOsm} / \mathrm{l}$ for the gluco-saline solution.

Infusion of the test meals and assessment of gastric retention were performed using standard laboratory methods $(15,16)$.

Results are presented graphically as box plots. In each box plot, the upper and lower horizontal lines represent the highest and lowest values in each group, respectively. The upper and lower borders of each box represent the first and third quartiles, respectively. The thick line within each box represents the median value.

For statistical analysis, the Mann-Whitney $(\mathrm{k}=2)$ and Kruskal-Wallis $(\mathrm{k}>2)$ tests for independent samples were used. The value of $\alpha$ in a two-tailed test was set at 0.05 for the first test and at 0.10 for the second one $(17,18)$. When there was a significant difference based on the Kruskal-Wallis test, a multiple comparison test was applied to differentiate between pairs, with the $\alpha$ value set at $0.02(19)$.

\section{Results}

\section{Phase 1: total water deprivation}

Figure 1A shows the gastric retention of 
Figure 1 - Gastric retention values for different test meals 10 min after orogastric administration to rats $(2 \mathrm{ml} / 100 \mathrm{~g})$. The results are presented as box plots for 10 rats in each group. In each box plot, the upper and lower horizontal lines represent the highest and lowest values in each group, respectively. The upper and lower borders of each box represent the first and third quartiles, respectively. The thick line within each box represents the median value. Striped boxes, Water-deprived rats; open boxes, non-deprived rats. $A$, Water deprivation for $24 \mathrm{~h}$; $B$, water deprivation for $48 \mathrm{~h}$; $C$, water deprivation for $72 \mathrm{~h}(\mathrm{P}<0.05$, Mann-Whitney test).

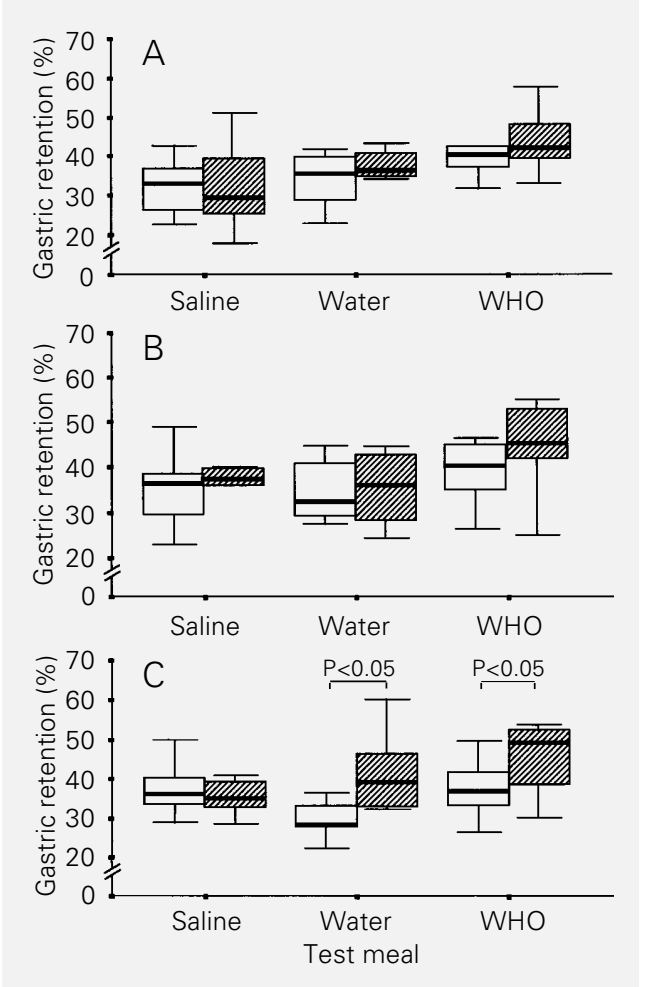

Figure 2 - Gastric retention values for different test meals 10 min after orogastric administration to rats $(2 \mathrm{ml} / 100 \mathrm{~g})$ in the 72-h water deprivation study. The results are presented as box plots for 10 rats in each group. For an explanation of the box plots, see the legend to Figure 1. A, No water deprivation (open boxes), total deprivation (striped boxes) and total water deprivation but with access to water for 60 min (grid boxes). B, No water deprivation (open boxes), total deprivation (striped boxes) and total water deprivation but with access to water for 120 min (grid boxes) $(P<0.02$, Kruskal-Wallis test).
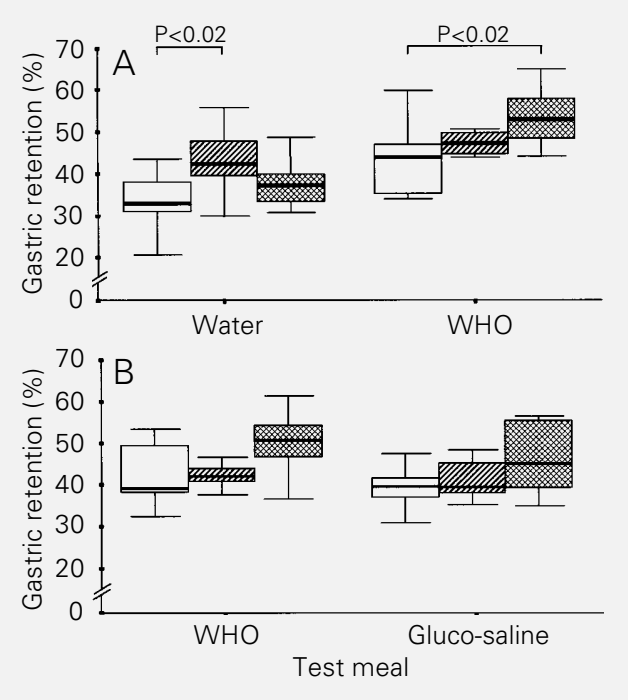

the test meals employed during water deprivation for $24 \mathrm{~h}$. There was no significant difference in the retentions of meals between the experimental and control groups. A similar result was obtained for animals deprived of water for $48 \mathrm{~h}$ (Figure 1B). However, when the duration of water deprivation was $72 \mathrm{~h}$ (Figure 1C), there was a significant difference $(\mathrm{P}<0.05)$ between the groups receiving test meals of water and rehydrating solution and control animals.

\section{Phase 2: partial deprivation with water offered for $60 \mathrm{~min}$}

Figure 2A illustrates the gastric retention of animals partially deprived of liquids (with water being offered for $60 \mathrm{~min}$ ) and controls. Water and rehydrating solution were used as the test meals. In the group given water as the test meal, a significantly greater retention, as described above for the group totally deprived of liquids, was observed $(\mathrm{P}<0.02)$ when compared to the non-deprived group. However, there was no significant difference in gastric retention between the partial deprivation group and the control group, showing a return to the initial gastric retention values. In the group receiving a test meal of the WHO rehydrating solution, the gastric retention was significantly greater in the animals with partial water deprivation than in the control group which received water $(\mathrm{P}<0.02)$. There was no difference between the latter group and the total liquid deprivation group.

\section{Phase 3: partial deprivation with water offered for $120 \mathrm{~min}$}

The gastric retention for these groups is shown in Figure 2B. There was no significant difference among the three groups of animals which received gluco-saline and rehydrating solutions as test meals. Nevertheless, in the animals receiving rehydrating solution, the gastric retention of the group with partial water deprivation was greater than in the groups with and without water deprivation, with a $\mathrm{P}$ value (0.04) close to significance.

\section{Discussion}

The model of dehydration used in the 
present study was based on water restriction for 24 to $72 \mathrm{~h}$ in rats in a laboratory environment maintained at neutral temperature (7). This model reproduces complete water deprivation without the interference of thermally regulated mechanisms which may be triggered in hyperthermal states $(3,20)$. The similar gastric retentions for the saline meal observed in the control and treated groups indicate the lack of involvement of mechanisms that regulate the gastric emptying of inert meals and the lack of influence of local control mechanisms in the gastrointestinal tract (11,21-23).

The lower gastric retentions observed for the saline and water test meals compared to the rehydrating solution reflected the influences of osmotic concentration and of the calorie content of the meals upon gastric emptying, as reported in other studies (2428 ). During the $72-\mathrm{h}$ period of water deprivation, greater gastric retention of the water and rehydrating solution meals were observed in the dehydrated group. Studies showing a relationship between alterations in the extracellular space and gastrointestinal motility also reported an accelerated gastric emptying in situations of hypovolemia $(29,30)$ and retardation of emptying under conditions of volume expansion (31). Other studies have demonstrated that the stomach (32) and the proximal jejunum (33) of dogs become less compliant during expansion and more relaxed following a decrease in extracellular volume. These observations indicate that acute changes in extracellular volume can modulate the contractile activity of the gastrointestinal tract. In the dehydration model used in this study, there is probably no involvement of the physiological responses released in an acute situation of extracellular volume retraction or hypovolemia. Since dehydration was established slowly, other adaptive mechanisms may have been activated in animals deprived of water. The retarded gastric emptying seen with water and the rehydrating solution in the case of dehydration may be explained by local mechanisms in the intestinal mucosa that modulate the gastric motor response. Thus, a reduction in the liquid present in the lateral intercellular space may inhibit the gastric emptying of solutions by acting as a transducer to regulate the motor activity of the stomach $(34,35)$. Animals which exhibited a state of dehydration probably had a general reduction in the water of their organ systems, including the enterocytes. The decrease in intracellular water in the enterocytes of the duodenal villi may have triggered an osmotic mechanism which directed the water flux into the cell, beginning with the lateral intercellular space. The subsequent collapse of the intercellular space may in turn have activated the inhibition of gastric emptying through the involvement of afferent vagus fibers (26) or hormones (36), independent of the test meal composition.

When these animals were offered water for 60 or $120 \mathrm{~min}$, an influx of water into the intercellular space may have occurred. Thereby, the rehydration and the reconstitution of the intercellular space may revert the inhibition of the gastric emptying. With the rehydrating solution and gluco-saline test meals, the retardation of gastric emptying was generally maintained, even after the offering of water. Since the solutions which showed retardation contain sodium and since water absorption and sodium transport in the jejunal mucosa are interdependent, these findings may be understood to represent a flux of liquids between the mucosa and serosa $(37,38)$. In the model of transcellular flux, sodium actively absorbed in the apical portion of the cell provokes an increase in cell tonus and results in an osmotic gradient with the intercellular space (38). The resulting influx of water tends to dilute the internal environment. In another model, the permeability of tight junctions is altered in the presence of sodium and an osmotic gradient, thereby leading to a flow of water in the mucosa-serosa direction, principally through 
the intercellular space (37).

Using an isolated loop of the small intestine of toads, Loeschke et al. (39) demonstrated that an osmotically induced liquid flux is more intense in the mucosa to serosa direction than in the opposite one. Ultrastructural studies carried out by the same authors showed that during the absorption of liquids, the lateral intercellular space is distended. When an osmotic flux occurs in the opposite direction, the lateral intercellular space collapses, thereby diminishing the influx of liquids. Similar results were obtained by Wright et al. (40) who demonstrated distention of the intercellular space when a hypertonic solution was applied to the serosa. When the mucosa was in contact with a hypertonic solution, the intercellular spaces collapsed, the resistance of the tissue increased and the permeability to solutions diminished.

In the presence of a solution with a high concentration of sodium and a balanced intracellular environment in the intestinal mu- cosa after the administration of water, the flux of liquids would tend to be in the serosa to mucosa direction, explaining the high sodium concentration present in the intestinal lumen. Such a sequence of events would cause the intercellular space to collapse (39) and lead to the inhibition of gastric emptying (24) which, in turn, would retard the exit of rehydrating solution from the stomach. The presence of intraluminal liquid containing a high level of sodium may have provoked changes in the selectivity and permeability of the tight junctions to cations and anions. Such selectivity to ions would produce a transjunctional electric potential which in turn would increase transepithelial resistance and diminish the flux of liquid in the mucosa to serosa direction (41).

Thus, in dehydration provoked by water deprivation with or without minimal alterations in body electrolyte content, the gastric emptying of the WHO rehydrating solution was delayed after rehydration with water.

\section{References}

1. Fitzsimons JT (1972). Thirst. Physiological Reviews, 52: 468-561.

2. Aukland K (1989). Is extracellular fluid volume regulated? Acta Physiologica Scandinavica, 136 (Suppl 583): 59-67.

3. Fitzsimons JT (1989). Bengt Andersson's pioneering demonstration of the hypothalamic "drinking area" and the subsequent osmoreceptor/sodium receptor controversy. Acta Physiologica Scandinavica, 136 (Suppl 583): 15-25.

4. Franci CR (1994). Aspects of neural and hormonal control of water and sodium balance. Brazilian Journal of Medical and Biological Research, 27: 885-903.

5. Okuno $T$, Yawata $T$, Nose $H$ \& Morimoto $T$ (1988). Difference in rehydration process due to salt concentration of drinking water in rats. Journal of Applied Physiology, 64: 2438-2443.

6. Greenleaf JE (1982). Dehydration-induced drinking in humans. Federation Proceedings, 41: 2509-2514.
7. Hainsworth FR \& Stricker EM (1971). Evaporative cooling in the rat: differences between salivary glands as thermoregulatory effectors. Canadian Journal of Physiology and Pharmacology, 49: 573-580.

8. World Health Organisation (1980). A Manual for the Treatment of Acute Diarrhea. WHO/CDD/SER/80.2. World Health Organisation/Programme for Control of Diarrheal Disease, Geneva, Switzerland.

9. Ghishan FK (1988). The transport of electrolytes in the gut and the use of oral rehydration solutions. Pediatric Clinics of North America, 35: 35-51.

10. Nalin DR, Cash RA, Islam R, Molla M \& Phillips RA (1968). Oral maintenance therapy for cholera in adults. Lancet, 2: 370-372.

11. Meyer JH (1987). Motility of the stomach and gastroduodenal junction. In: Johnson LR (Editor), Physiology of the Gastrointestinal Tract. 2nd edn. Raven Press, New York, 613-629.
12. Raybould HE \& Taché $Y$ (1988). Cholecystokinin inhibits gastric motility and emptying via a capsaicin-sensitive vagal pathway in rats. American Journal of Physiology, 255: G242-G246.

13. Flanagan LM, Verbalis JG \& Stricker EM (1989). Effects of anorexigenic treatments on gastric motility in rats. American Journal of Physiology, 256: R955-R961.

14. Schwartz GJ, Berkow G, McHugh PR \& Moran TH (1993). Gastric branch vagotomy blocks nutrient and cholecystokinin-induced suppression of gastric emptying. American Journal of Physiology, 264: R630-R637.

15. Belangero VMS \& Collares EF (1991) Esvaziamento gástrico e acidose metabólica. I. Estudo de um modelo experimental em ratos, empregando uma solução de cloreto de amônio por via orogástrica. Arquivos de Gastroenterologia, 28: 145150 
16. Bucaretchi F \& Collares EF (1996). Effect of Phoneutra nigriventerspider venom on gastric emptying in rats. Brazilian Journal of Medical and Biological Research, 29: 205-211.

17. Siegel S (1975). O caso de duas amostras independentes. In: Estatística Não-Paramétrica. McGraw-Hill, São Paulo, 106-180.

18. Siegel S (1975). O caso de k amostras independentes. In: Estatística Não-Paramétrica. McGraw-Hill, São Paulo, 197-219.

19. Leach C (1979). Tests for several independent samples - categorical explanatory variable. In: Leach C (Editor), Introduction to Statistics. A Nonparametric Approach for the Social Sciences. John Wiley and Sons, Chichester, New York, 148168.

20. McCann SM, Franci CR \& AntunesRodrigues J (1989). Hormonal control of water and electrolyte intake and output. Acta Physiologica Scandinavica, 136 (Suppl 583): 97-104.

21. Brener $W$, Hendrix $T R \&$ McHugh $P R$ (1983). Regulation of the gastric emptying of glucose. Gastroenterology, 85: 7682.

22. Thomas JE \& Baldwin MV (1968). Pathways and mechanisms of regulation of gastric motility. In: Code CF (Editor), Handbook of Physiology. Alimentary Canal. Vol. 4. American Physiological Society, Washington, DC, 1937-1968.

23. Kelly KA (1980). Gastric emptying of liquids and solids: roles of proximal and distal stomach. American Journal of Physio-ogy, 239: G71-G76.

24. McHugh PR \& Moran TH (1979). Calories and gastric emptying: a regulatory capacity with implications for feeding. American Journal of Physiology, 236: R254R260.
25. Hunt JN \& Pathak JD (1960). The osmotic effects of some simple molecules and ions on gastric emptying. Journal of Physiology, 154: 254-269.

26. Hunt JN \& Stubbs DF (1975). The volume and energy content of meals as determinants of gastric emptying. Journal of Physiology, 245: 209-225.

27. Meeroff JC, Go VLW \& Phillips SF (1975). Control of gastric emptying by osmolality of duodenal contents in man. Gastroenterology, 68: 1144-1151.

28. Hunt JN (1983). Mechanisms and disorders of gastric emptying. Annual Review of Medicine, 34: 219-229.

29. Santos AA, Xavier-Neto J, Pereira JM, Gondim FAA, Santiago Jr AT, Capelo LR \& Rola FH (1988). Acute changes in extracellular fluid volume modify the antroduodenal flow of saline in dogs: a possible physiological role. Brazilian Journal of Medical and Biological Research, 21: 1083-1087.

30. Santos AA, Xavier-Neto J, Santiago Jr AT, Souza MAN, Martins AS, Alzamora F \& Rola FH (1991). Acute volaemic changes modify the gastroduodenal resistance to the flow of saline in anaesthetized dogs. Acta Physiologica Scandinavica, 143: 261269.

31. Xavier-Neto J, Santos AA \& Rola FH (1990). Acute hypervolaemia increases gastroduodenal resistance to the flow of liquid in the rat. Gut, 31: 1006-1010.

32. Capelo LR, Cavalcante DM, Leitão IA, Filho GC \& Da-Silva EAT (1983). Modifications of gastric compliance in dogs related to changes of extracellular fluid volume: a possible physiological role. Brazilian Journal of Medical and Biological Research, 16: 73-76.

33. Rola FH, Santos AA, Xavier-Neto J, Cristino-Filho G, Rocha Cl, Santiago Jr AT, Gondim FAA, Pereira JM \& Capelo LR (1989). Effects of acute volemic changes on jejunal compliance in dogs. Brazilian Journal of Medical and Biological Research, 22: 523-531.
34. Hunt JN (1983). Does calcium mediate slowing of gastric emptying by fat in humans? American Journal of Physiology, 244: G89-G94.

35. Barker GR, Cochrane GM, Corbett GA, Dufton JF, Hunt JN \& Roberts SK (1978). Glucose, glycine and diglycine in test meals as stimuli to a duodenal osmoreceptor slowing gastric emptying. Journal of Physiology, 283: 341-346.

36. Grossman MI (1974). Candidate hormones of the gut. Gastroenterology, 67: 730-755.

37. Schultz SG, Frizzell RA \& Nellans HN (1974). Ion transport by mammalian small intestine. Annual Review of Physiology, 36: 51-91.

38. Armstrong WM (1987). Cellular mechanisms of ion transport in the small intestine. In: Johnson LR (Editor), Physiology of the Gastrointestinal Tract. 2nd edn. Raven Press, New York, 1251-1265.

39. Loeschke K, Bentzel CJ \& Czáky TZ (1970). Asymmetry of osmotic flow in frog intestine: functional and structural correlation. American Journal of Physiology, 218: 1723-1731.

40. Wright EM, Smulders AP \& Tormey J McD (1972). The role of the lateral intercellular spaces and solute polarization effects in the passive flow of water across rabbit gallbladder. Journal of Membrane Biology, 7: 198-219.

41. Madara JL (1983). Increases in guinea pig small intestinal transepithelial resistance induced by osmotic loads are accompanied by rapid alterations in absorptive-cell tight-junction structure. Journal of Cell Biology, 97: 125-136. 